\title{
Strategi Pragmatik dalam Penciptaan Humor di Televisi
}

\author{
Riris Tiani \\ Fakultas Ilmu Budaya, Universitas Diponegoro \\ Email: tiani.riris@gmail.com
}

\begin{abstract}
Humors function not only just entertain, but also has educated function viewer to think creative. This study aims to determine the pragmatic strategy in the creation of humor that aired on some Indonesian television. The research domain uses the assessment of the humorous theory of Asa Berger. The unit of analysis of this research are words, phrases, and sentences as verbal markers of speech humor. The results of research include misunderstanding techniques with idiom meaning of a word that raises a different meaning; The technique of deceiving by asking a question and a sentence indirectly outwits the other person, so the humorist looks smarter than his opponent; Mocking technique by directly criticizing the speaker because his speech sounds weird; And sound-playing techniques by replacing a phoneme in a word which then creates a different meaning.
\end{abstract}

Keywords: pragmatic strategy, humor theory, words, phrases, sentences.

\section{Intisari}

Humor tidak hanya memiliki fungsi menghibur saja, tetapi juga berfungsi mendidik penonton sehingga mampu berpikir kreatif. Penelitian ini untuk mendeskripsikan strategi prakmatik dalam penciptaan humor di Televisi. Kajian penelitian ini menggunakan teori humor Asa Berger. Unit analisis penelitian ini adalah kata, frasa, kalimat sebagai penanda tuturan humor. Hasil penelitian ini meliputi teknik kesalahpahaman dilakukan dengan kemajemukkan makna suatu kata sehingga menimbulkan makna yang ditangkap berbeda; teknik mengecoh dilakukan dengan memberiikan pertanyaan dan juga suatu kalimat yang secara tidak langsung mengecoh lawan bicara, sehingga si pencetus humor dapat terlihat lebih pintar dibandingkan lawannya; teknik ejekan dilakukan dengan mencela secara langsung lawan bicara karena ucapannya yang terdengar aneh; dan teknik permainan bunyi dilakukan dengan penggantian sstu fonem pada suatu kata yang kemudian menimbulkan arti berbeda.

Kata kunci: strategi pragmatik, teori humor, kata, frasa, kalimat. 


\section{Pendahuluan}

Dewasa ini kerap bermunculan acara humor dengan berbagai jenis dan fungsinya masingmasing. Salah satunya adalah acara humor yang memiliki nilai edukatif sehingga mampu menambah pengetahuan dan memperluas cara berpikir penontonnya. Humor yang seperti ini akhir-akhir ini cukup diminati oleh masyarakat yang berpendidikan.

Penciptaan humor dalam acara humor yang memiliki muatan pendidikan cenderung dikemas dalam bahasa yang santun dan dibutuhkan proses berpikir serta wawasan untuk memahami isi humor tersebut. Humor dalam acara seperti ini lebih memiliki kualitas karena tidak hanya menimbulkan tawa, tetapi juga kemampuan menyesuaikan konteks humor yang dibawakan. Muatan humor seperti ini dapat ditemukan pada acara humor "Waktu Indonesia Bercanda" di saluran televisi Net.

Penciptaan humor dalam "Waktu Indonesia Bercanda" berfokus pada aspek bahasa menggunakan berbagai teknik hingga terciptalah kesan lucu dan menimbulkan tawa penontonnya. Terkait dengan permasalahan tersebut maka penulis dalam penelitian ini bermaksud meneliti teknik penciptaan humor melalui aspek bahasa seperti apa yang digunakan sebagai upaya penciptaan humor dalam acara "Waktu Indonesia Bercanda" di Net TV.

Riris (2016) dalam penelitiannya yang berjudul "Penyimpangan Maksim Kualitas dan Kuantitas dalam "Humor Sutra" di Tabloid Mantra" menjelaskan beberapa penyimpangan prinsip kerjasama yang dapat mendukung dalam penciptaan humor pada sebuah tabloid. Menurut Riris, penyimpangan yang terjadi dalam tabloid tersebut berupa: 1) penyimpangan maksim kuantitas berupa informasi berlebihan dan informasi kurang informatif, 2) penyimpangan maksim kualitas berupa informasi salah dan informasi tidak logis. Data penelitian Riris merupakan kata, frasa, dan kalimat yang mengandung daya penyimpangan maksim kualitas dan maksim kuantitas menggunakan kajian pragmatik. Data tersebut berbentuk percakapan dan juga narasi.

Leech (1993: 8), menyatakan bahwa pragmatik adalah studi tentang makna dalam hubungannya dengan situasi-situasi ujar. Situasi ujar tersebut dapat meliputi penutur dan lawan tutur, konteks tuturan, tujuan tuturan, tuturan sebagai bentuk tindakan atau aktivitas, tuturan sebagai produk tindak verbal.

Bahasa diperlakukan secara pragmatik artinya adalah bahasa diperlakukan dengan mempertimbangkan konteksnya, yakni penggunaan pada peristiwa komunikasi. Adapun yang 
dihantam oleh aliran pragmatik ialah tindakan aliran struktural yang melucuti kalimat yang pada hakikatnya berkonteks karena digunakan dalam komunikasi (Purwo, 1990: 16).

Wijana (2004: 37) menyatakan bahwa humor pada hakikatnya adalah rangsangan yang menyebabkan seseorang tertawa atau tersenyum dalam kebahagiaan. Dalam kaitan ini ada tiga aspek yang layak diperhatikan, yakni tindakan verbal atau nonverbal yang merupakan stimulusnya, aktivitas kognitif dan intelektual sebagai alat persepsi dan evaluasi rangsangan itu, dan respon yang dinyatakan dengan senyum dan tawa.

Arthur Asa Berger (2005: 83) mengatakan bahwa ada 45 teknik penciptaan humor yang dapat digolongkan dalam empata kategori, meliputi: bahasa atau language (the humor is verbal), logika atau logic (the humor is ideation), bentuk atau identity (the humor is existensial), gerakan atau action (the humor is physical). Penelitian ini, penulis hanya menggunakan teknik penciptaan humor menggunakan media bahasa sebagai pisau analisis.

Penciptaan humor Berger (dalam Anastasya, 2013: 5) dapat diidentifikasikan sebagai berikut: sindiran, mengecoh, definisi, melebih-lebihkan, ejekan, ironi, kesalahpahaman, permainan bunyi, permainan kata, sarkasme, satire.

\section{Metode Penelitian}

Penelitian ini merupakan penelitian deskriptif kualitatif. Dengan objek kajian tuturan pemain acara humor Waktu Indonesia Bercanda di Net Tv. Pengumpulan data menggunakan metode simak dan teknik rekam dan catat. Lalu direduksi sesuai kebutuhan penelitian kemudian dianalisis menggunakan kajian teori humor Asa Berger.

\section{Pembahasan: Penciptaan Humor Melalui Aspek Bahasa}

Acara humor "Waktu Indonesia Bercanda" teknik yang dilakukan oleh para komedian yang terlibat di dalamnya menggunakan teknik penciptaan humor melalui media bahasa atau language (the humor is verbal). Teknik yang digunakan dalam pemakaian bahasa sebagai media humor oleh para komedian adalah teknik kesalahpahaman, teknik mengecoh, teknik ejekan, dan teknik permainan bunyi. 


\section{Penciptaan Humor Melalui Aspek Bahasa dengan Teknik Kesalahpahaman}

Dengan teknik kesalahpahaman, komedian yang satu dengan yang lainnya membicarakan suatu

hal yang keduanya saling salah tangkap atau salah pengertian. Berikut adalah percakapan dalam acara humor "Waktu Indonesia Bercanda" yang menggunakan teknik kesalahpahaman:

(1) (WIB/10 April 2017/TTS)

Cak Lontong : :Tujuh mendatar ada enam kotak. Yang biasa dikasih pita... Ada huruf 'I' di kotak kelima"

Bedu : : "Anak kecil juga dikasih pita, Pak."

Cak Lontong : : "Ya udah jawab aja anak kecil."

Bedu : "Ya nggak cukup, Pak."

Cak Lontong : "Ya dicukup-cukupin, kan anaknya kecil. Kalau nggak cukup ya dipaku."

Konteks percakapan (1) mengenai percakapan Cak Lontong dengan Bedu mengalami perubahan konteks yang bersumber dari kesalahpahaman. Kemajemukan terhadap pandangan kata 'anak kecil' antara Cak Lontong dan Bedu inilah yang menjadi penyebab kesalahpahaman. 'Anak kecil' yang dimaksud oleh Bedu berupa tulisan verbal saja yang tidak cukup jika ditulis ke dalam kotak TTS yang jumlahnya enam kotak. Cak Lontong dengan sengaja membuat kesalahpahaman mengenai 'anak kecil' tersebut menjadi sebuah benda nyata (benar-benar anak yang berwujud) untuk dimasukkan kedalam kotak.

Dalam humor, teknik kesalahpahaman sengaja dimunculkan sebagai salah satu cara untuk membuat efek kelucuan. Hanya saja, tidak semua penonton dapat langsung memahami maksud dari pelawak. Pada teknik ini ada fungsi positif lain yang didapat penonton, bahwa penonton diajak untuk berpikir kreatif, mencermati setiap kelakar dan gerakan pelawak dalam menciptakan efek lucu. Seringkali efek lucu muncul secara spontanitas di atas panggung.

\section{Penciptaan Humor Melalui Aspek Bahasa dengan Teknik Mengecoh}

Dengan teknik mengecoh, humor diciptakan untuk mengalahkan kepintaran seseorang dengan melontarkan pertanyaan atau pernyataan. Berikut adalah percakapan dalam acara humor "Waktu Indonesia Bercanda" yang menggunakan teknik mengecoh:

(2) (WIB/10 April 2017/TTS)

Cak Lontong : : Nomor berapa?" 


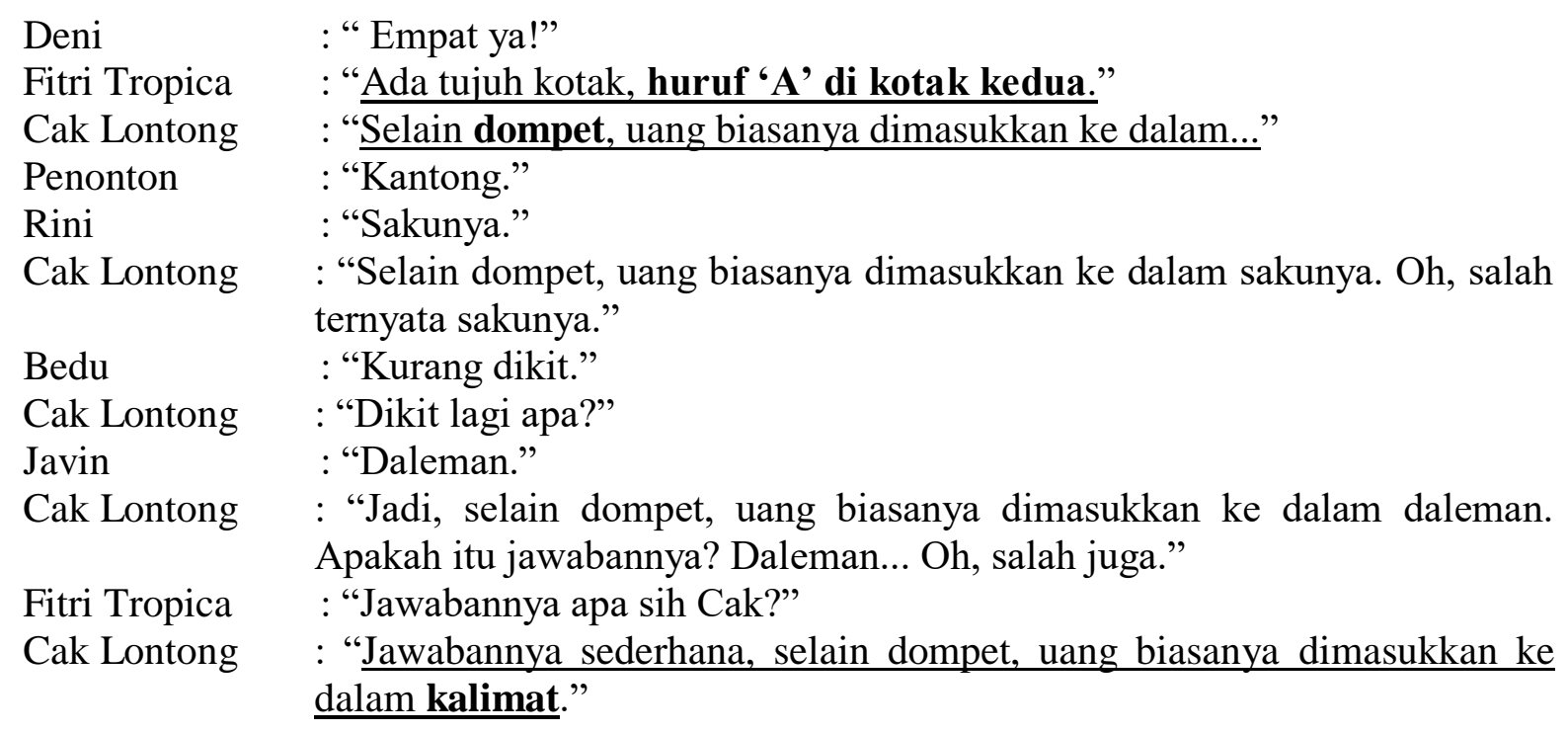

Konteks wacana di atas mengenai percakapan antara Cak Lontong dan para peserta di acara tersebut, yaitu Deni dan Rini, serta Bedu dan Javin dalam segmen pertama TTS (Teka-teki Sulit). Pertanyaan Cak Lontong yang terdapat pada percakapan (2) secara umum akan dijawab oleh mitra tuturnya dengan kata yang sejenis dengan dompet atau kata lain dengan kategori nomina yang berwujud. Tidak salah jika penonton mencoba menjawab teka-teki tersebut dengan jawaban 'kantong' dan juga sudah ada bantuan huruf 'A' pada kotak kedua. Terdapat pula jawaban yang diberikan oleh Rini dan Javin, masih masuk akal, karena kedua kata tersebut masih satu kategori dengan dompet. Akan tetapi, Cak Lontong ternyata tidak memberikan jawaban sesuai dengan pandangan objektif. Pembanding 'dompet' yang ia berikan sebagai pentunjuk secara tidak langsung ternyata tidak difungsikan sebagaimana khalayak lain memandang fungsi kata tersebut. Cak Lontong memberitahukan bahwa jawaban yang benar adalah 'kalimat', seperti yang terdapat pada teks percakapan yang bergaris bawah. Di sini klimaks humor atau kelucuan dalam percakapan (2).

Sudut pandang Cak Lontong tidak objektif. Ia mengubah sudut pandang yang digunakan sesuai dengan subjektivitasnya (mengecoh sudut pandang), sehingga diperlukan waktu bagi khalayak untuk memikirkan jawaban tersebut. Cak Lontong mengubah relevansi antara dompet sebagai pembanding dengan jawaban yang akan muncul. Dompet adalah benda yang berwujud, sedangkan kalimat merupakan sesuatu yang abstrak meskipun masih dalam satu kategori nomina. Melalui kalimat yang diucapkan Fitri Tropica dan Cak Lontong yang secara berturut- 
turut digarisbawahi merupakan bukti pengecohan yang dilakukan untuk mendapatkan kesan lucu.

(3) Cak Lontong

Bedu
Cak Lontong
Bedu
Cak Lontong

Bedu

Cak Lontong

Bedu

Peppy

Bedu

Deni

Bedu

Deni

Bedu

Cak Lontong
: "Tujuh mendatar ada enam kotak. Yang biasa dikasih pita... Ada huruf 'I' di kotak kelima.'

: "Anak kecil juga dikasih pita, Pak."

:"Yaudah jawab aja anak kecil."

: "Ya nggak cukup, Pak."

: "Ya dicukup-cukupin, kan anaknya kecil. Kalau nggak cukup ya dipaku."

: "Karena Bapak minta dicukup-cukupin, kita mencoba menjawab untuk dicukup-cukupin. Jadi ini padanan atau paling nggak sama dengan anak kecil. Balita."

: "Balita?"

: "Yang biasanya dikasih pita. Kado buat suaminya. Sayang, aku punya hadiah buat kamu. Anak kita udah lahir. Dipitain."

:"Heh, Bedu. Bayi, bayi mana ada yang dikasih pita?"

: "Ya biar lucu aja."

:"Ya kalau buat lucu, lo jawab aja cacing juga lucu."

: "Cacing mana ada yang dikasih pita."

: "Ya emang ada. Lha kenapa namanya cacing pita?"

: "Oh iya cacing juga bisa. Cacing aja udah."

: “Ok. Cacing, kita kunci jawaban Bedu. Yang biasa dikasih pita... cacing. Yak betul."

Percakapan (3) terjadi pengecohan yang dilakukan Cak Lontong melalui soal yang diberikan. Lazimnya orang akan berpikir bahwa susuatu yang diberi pita adalah hadiah, terlebih lagi dalam kalimat yang bergaris bawah tersebut terdapat bantuan huruf 'I' pada kotak kelima yang semakin menguatkan. Namun, para komedian lain sudah memahami bahwa pertanyaan dan bantuan jawaban tersebut merupakan pengecohan yang dilakukan Cak Lontong. Pengecohan itu terbukti dengan jawaban akhir yang berupa kata 'cacing'. Meskipun pengecohan tersebut tidak berhasil secara mutlak, namun upaya yang dilakukan Cak Lontong untuk mengalahkan kepintaran lawan bicaranya melalui pertanyaan tersebut tetap memberikan kesan lucu. Lawannya harus berpikir terlebih dahulu agar bisa memberikan jawaban dan tidak terkecoh pada bantuan huruf 'I' dan alur pertanyaan yang diberikan oleh Cak Lontong.

Pengecohan sengaja dilakukan untuk menciptakan efek lucu. Terkadang pengecohan juga sengaja untuk dilanggar agar efek lucu semakin terlihat. Dalam tuturan (3) tampak jawaban dari TTS bisa mudah ditebak oleh lawan tutur lain karena lawan tutur lain sengaja melanggar realitas atas jawaban yang sebenarnya. Aka tetapi lawan tutur juga menerapkan teknik mengecoh untuk 
menjawab pertanyaan dari lawan tutur dan jawaban yang disampaikan justru sesuai dengan yang dimaksud penutur.

(4) (WIB/10 April 2017/TTS)

Cak Lontong : "Yang biasa dipasang di depan gang... Biasanya bisa gambar pahlawan."

Deni : "Yaudah, warung deh."

Cak Lontong : "Yang biasa dipasang di depan gang adalah... menung."

Peppy : :"Menung?"

Deni : "Menung. Menunggang."

Percakapan (4) terjadi usaha pengecohan konteks yang dilakukan Cak Lontong kepada Deni sebagai peserta. Pertanyaan dari Cak Lontong konteksnya merujuk kepada benda yang biasa ditaruh di depan sebuah gang, terlebih disertai unsur pengecoh yaitu "Biasanya bisa gambar pahlawan”. Secara tidak langsung, kata-kata tersebut akan menuntun orang yang mendengar pertanyaan untuk menjawab dengan sesuatu yang serupa dengan gambar pahlawan, yaitu berupa benda yanng berwujud. Saat Cak Lontong melontarkan jawabannya adalah 'menung', konteks dari pertanyaan tersebut seketika berubah, bukan 'gang' yang merupakan nomina, tetapi 'gang' yang dimaksud adalah penggalan dari kata 'menunggang'. Cak Lontong berhasil mengecoh peserta dengan pertanyaan tersebut.

\section{Penciptaan Humor Melalui Aspek Bahasa dengan Teknik Ejekan}

Dengan teknik ejekan, humor diciptakan dengan dengan ejekan atau celaan secara langsung. Berikut adalah percakapan dalam acara humor "Waktu Indonesia Bercanda" yang menggunakan teknik ejekan:

(5) (WIB/10 April 2017/TTS)

Cak Lontong : "Deni memilih nomor berapa?"

Deni : "Tiga mendatar."

Cak Lontong : : "Baik, tiga mendatar ya."

Fitri Tropica : "Sembilan kotak. Huruf 'A' di kotak ke tujuh."

Cak Lontong : "Kendaraan yang berjalan di atas rel..."

Deni : "Jawabannya kereta api, tapi nggak mungkin."

Cak Lontong : : "Anda menyangkal akal sehat Anda sendiri?"

Percakapan (5) terdapat ejekan yang dilontarkan secara langsung oleh Cak Lontong kepada Deni. Kalimat dalam percakapan yang bergaris bawah merupakan bukti ejekan yang dilontarkan 
oleh Cak Lontong. Ejekan yang dilontarkan merupakan sebuah pertanyaan yang mencela Deni berdasarkan pada ucapan Deni yang memang aneh untuk di dengar.

Teknik ejekan ada beberapa jenis, salah satunya adalah ejekan berdasar ketidaksepakatan secara verbal. Pada tuturan (5) lawan tutur merasa tidak percaya diri atas jawaban yang sudah diucapkan. Alasan lawan tutur tidak yakin karena lawan tutur memahami teknik kelucuan yang digunakan penutur dari awal menggunakan teknik mengecoh, sehingga apabila dijawab sesuai dengan realita yang benar jawaban akan menjadi salah di mata penutur. Akan tetapi, lawan tutur sudah berusaha menjawab dengan jawaban yang mengecoh juga dan masih tidak percaya diri dengan mengucapkan kata "tidak mungkin". Padahal sesuai realita, semua moda transportasi yang berjalan di atas rel pasti kereta. Rasa tidak percaya diri itu menjadi momentum Cak Lontong untuk memunculkan efek kelucuan dengan mencela lawan tuturnya secara halus dengan cara menunjukkan kebodohan lawan tutur sendiri.

\section{Penciptaan Humor Melalui Aspek Bahasa dengan Teknik Permainan Bunyi}

Dengan teknik permainan kata, humor diciptakan dengan mempermainkan bunyi bahasa. Berikut adalah percakapan dalam acara humor "Waktu Indonesia Bercanda" yang menggunakan teknik permainan bunyi:

(6) (WIB/10 April 2017/TTS)

$\begin{array}{ll}\text { Cak Lontong } & \text { : "Deni memilih nomor berapa?" } \\ \text { Deni } & \text { :"Tiga mendatar." } \\ \text { Cak Lontong } & \text { :"Baik, tiga mendatar ya." } \\ \text { Fitri Tropica } & \text { :"Sembilan kotak. Huruf "A' di kotak ke tujuh." } \\ \text { Cak Lontong } & : \text { "Kendaraan yang berjalan di atas rel..." } \\ \text { Deni } & \text { :"Jawabannya kereta api, tapi nggak mungkin." } \\ \text { Cak Lontong } & \text { :"Anda menyangkal akal sehat Anda sendiri?" } \\ \text { Rini } & \text { : "Di sini nggak ada yang pakai akal sehat. Yang dipakai } \\ \text { Deni } & \text { logika." "Bukan logika juga. Di sini yang dipake logila." }\end{array}$

Percakapan (6) terdapat teknik permainan bunyi untuk menimbulkan kelucuan. Kata logika diubah bunyinya menjadi logila yang memberikan efek kelucuan karena makna dari kedua kata yang hampir mirip bunyinya itu bertentangan. Logika dalam KBBI berarti jalan pikiran yang masuk akal, sedangkan logila merupakan suatu bentuk umpatan atas seseorang yang tidak waras, 
yaitu 'lo gila' (kamu gila). Perubahan bunyi fonem /k/ menjadi /1/ merupakan hal yang membuat kelucuan dalam percakapan ini.

Permainan bahasa logika menjadi logila secara sepontan menimbulkan efek kelucuan. Dengan sengaja Deni mengucapkan itu karena secara realita permainan TTS yang diberikan Cak Lontong tidak satupun memberikan pertanyaan dan jawaban dengan sewajarnya. Sehingga secara psikologis bagi Deni hanya orang yang memiliki kegilaan cerdas saja yang bisa menjawab pertanyaan dari Cak Lontong.

\section{Simpulan}

Penciptaan humor dalam acara humor Waktu Indonesia Bercanda dilakukan melalui aspek bahasa dengan teknik kesalahpahaman, mengecoh, ejekan, dan permainan bunyi. Teknik kesalahpahaman dilakukan dengan kemajemukkan makna suatu kata sehingga menimbulkan makna yang ditangkap berbeda; teknik mengecoh dilakukan dengan memberiikan pertanyaan dan juga suatu kalimat yang secara tidak langsung mengecoh lawan bicara, sehingga si pencetus humor dapat terlihat lebih pintar dibandingkan lawannya; teknik ejekan dilakukan dengan mencela secara langsung lawan bicara karena ucapannya yang terdengar aneh; dan teknik permainan bunyi dilakukan dengan penggantian sstu fonem pada suatu kata yang kemudian menimbulkan arti berbeda.

\section{Daftar Pustaka}

Anastasya, Sicilia. 2013. "Teknik-teknik Humor dalam Program Komedi di Televisi Swasta Nasional Indonesia" dalam Jurnal E-Komunikasi Vol. 1 No. 1. Surabaya: Universitas Kristen Petra.

Berger, Arthur Asa. 2005. Tanda-tanda dalam Kebudayaan Kontemporer: Suatu Pengantar Semiotika. Yogyakarta: Tiara Wacana.

Mahsun. 2005. Metode Penelitian Bahasa. Edisi Revisi. Jakarta: Raja Grafindo Persada.

Leech, Geoffrey. 1993. Prinsip-prinsip Pragmatik (terjemahan M.D.D. Oka). Jakarta: UI Press.

Rahmandji, Didiek. 2007. "Sejarah, Teori, dan Fungsi Humor" dalam Jurnal Tahun 35, Nomor 2. Malang: Seni dan Desain FS Universitas Negeri Malang.

Purwo, Bambang Kaswanti. 1990. Pragmatik dan Pengajaran Bahasa: Menyibak Kurikulum 1984. Yogyakarta: Kanisius.

Sudaryanto. 2015. Metode dan Aneka Teknik Analisis Bahasa: Pengantar Penelitian Wahana Kebudayaan secara Linguistis. Yogyakarta: Sanata Dharma University Press.

Wijana, I Dewa Putu. 1996. Dasar-dasar Pragmatik. Yogyakarta: Andi. . 2004. Kartun. Yogyakarta: Ombak. dan Rohmadi. 2006. Sosiolinguistik: Kajian Teori dan Analisis. Yogyakarta: Pustaka Pelajar. 
